\title{
The Impact of Feedback-seeking on Sources' Job Satisfaction: A Study of Canadian Supervisors
}

\author{
Joe Krasman \\ University of Ontario Institute of Technology \\ Igor Kotlyar \\ University of Ontario Institute of Technology
}

This study examines the impact of feedback-seeking on the source; that is, the person who is asked for feedback. A survey was conducted of full-time working supervisors from various industries in Canada. Results showed that frequency of being sought for feedback was positively related to supervisors' satisfaction with authority, satisfaction with security, and satisfaction with creativity. Frequency of being sought for feedback was also hypothesized to be positively related to supervisors' satisfaction with variety, however, no relationship was found.

\section{INTRODUCTION}

Feedback-seeking behavior (hereafter referred to as feedback-seeking) occurs when one party - the seeker - attempts to obtain feedback from another party - the source (Ashford \& Cummings, 1983; Ashford et al., 2016). An example of feedback-seeking is a subordinate (i.e. seeker) asking his or her supervisor (i.e. source), "Is this right?" or "Am I going about this the right way?" The concept of feedback-seeking was introduced by Ashford and Cummings (1983) over 30 years ago. Since that time, research on the topic has proliferated and a large literature has developed (for recent reviews and metaanalyses see Anseel et al., 2015; Ashford et al., 2016).

Research has shown that feedback-seeking can positively affect the seeker in various ways, for example, by increasing the seeker's job satisfaction, learning, task performance, and creative performance (Ashford et al., 2016). Ashford and colleagues (2018) recently showed that feedback-seeking can also positively affect the organization by increasing corporate financial performance. Because of these and other benefits that feedback-seeking can offer, researchers have recommended that organizations should encourage feedback-seeking in the workplace (Anseel et al., 2015; Madzar ,1995). Indeed, several organizations have developed smartphone apps that enable their employees to seek feedback on demand (Cappelli \& Tavis, 2016).

If feedback-seeking is to be promoted in the workplace, it should be important to consider its impact on the source. Recall that sources are the parties from whom feedback is sought, hence, each feedbackseeking interaction requires a source. Despite this, we know very little about the manner in which sources may be affected by feedback-seeking. For example, it has not been clearly established whether sources like or dislike being sought for feedback or whether they are advantaged or disadvantaged by it (Krasman, 
2018). While prior research has shown that feedback-seeking can be advantageous to the seeker and the organization, it cannot be concluded that the same holds true for the source.

In the two latest reviews of the feedback-seeking literature, Anseel and colleagues (2015) and Ashford and colleagues (2016) called for more research in this area. Since that time, Krasman (2018) conducted a field study and showed that if supervisors are asked for feedback too often, they can fall behind in their work and experience role overload and stress. The purpose of this study is to further increase our knowledge in this area by identifying other effects that feedback-seeking may have on sources. Specifically, this study will examine the impact of feedback-seeking on sources' job satisfaction. Prior research has shown that feedback-seeking can enhance the job satisfaction of seekers (Morrison, 1993). This study will shed light on whether it can also affect the job satisfaction of sources.

\section{THEORETICAL BACKGROUND}

As noted, feedback-seeking occurs when a seeker attempts to obtain feedback from a source. Prior to Ashford and Cummings' (1983) seminal article, feedback was predominately viewed as information that individuals passively receive, for example, when a supervisor decides to provide it or during the annual performance review (Ilgen et al., 1979). Ashford and Cummings (1983) argued that in addition to passively receiving feedback, people can also proactively seek it.

Feedback-seeking can be understood as a three-stage process (Ashford \& Cummings, 1983). In the first stage - motivation - the seeker becomes motivated to seek feedback. In the second stage - cognitive processing - the seeker weighs the costs and benefits of seeking feedback and formulates a feedbackseeking strategy. For example, the seeker decides whether to seek feedback, which source to seek feedback from, when to seek feedback, and how to seek feedback. In the final stage of the process behavior - the seeker carries out his or her strategy.

Feedback can be sought from subordinates, coworkers, supervisors, documentation (e.g. procedures manuals), and other sources (Ashford, 1993). In addition, feedback can be sought using various tactics such as asking for it directly, asking for it indirectly, and inferring it from observation (Ashford \& Cummings, 1983; Miller \& Jablin, 1991). Consistent with most feedback-seeking research, this study, will focus on full-time working supervisors as the source of feedback and on the number of times they are directly asked for feedback by their subordinates, coworkers, and own supervisors (Ashford et al., 2003).

Job satisfaction is an attitude and refers to "a pleasurable or positive emotional state resulting from the appraisal of one's job or job experiences" (Locke, 1976, p. 1300). According to job satisfaction theory, a person's overall job satisfaction is comprised of his or her satisfaction with various facets of the job (Spector, 1997). Several facet conceptualizations of job satisfaction have been put forth by researchers. For example, according to Smith and colleagues' (1969) model, job satisfaction is comprised of five facets whereas according to Spector's model (1985) job satisfaction is comprised of nine facets.

Weiss and colleagues (1967) developed one of the most comprehensive facet conceptualizations of job satisfaction. According to their model, job satisfaction is comprised of 20 facets. The researchers further developed the Minnesota Satisfaction Questionnaire (MSQ) to measure each facet. The MSQ is one of the most widely used measures of job satisfaction (Saari \& Judge, 2004).

This study will focus on four of Weiss and colleagues' (1967) facets, namely, satisfaction with authority, satisfaction with security, satisfaction with creativity, and satisfaction with variety. Specifically, this study will examine the relationship between the number of times sources are sought for feedback and their satisfaction with each of these facets. These facets were chosen based on their a priori logical and theoretical connection to frequency of being sought for feedback. For example, frequency of being sought for feedback was not deemed to be connected to the facet of satisfaction with working conditions which includes satisfaction with heating, lighting, and ventilation (Weiss et al., 1967). 


\section{HYPOTHESIS DEVELOPMENT}

Weiss and colleagues (1967) define satisfaction with authority as satisfaction with "the chance to tell other people what to do" (p. 1). When sources are sought for feedback, they are provided with an opportunity to influence how seekers proceed with their work. For example, sources may influence whether seekers make changes to their work, what changes they make, and how they make them. Having the opportunity to influence sources in this way is not merely a byproduct of being sought for feedback. Indeed, the very reason seekers are approaching sources in the first place is to be influenced in this

manner. Specifically, seekers are trying to determine "the correctness and adequacy of behaviors for attaining valued end states" (Ashford, 1986, p. 466). In this manner, being sought for feedback should facilitate opportunities for sources to experience authority in their job. As such, the more sources are sought for feedback, the more satisfied they should be with this facet of their job. In support of the above, research has shown that when subordinates are invited to provide upward feedback on their supervisor and influence their supervisor's performance appraisal, their job satisfaction increases (Hall et al., 1996). Based on the above, the following hypothesis is put forth:

Hypothesis 1: There is a positive relationship between frequency of being sought for feedback and satisfaction with authority.

Weiss and colleagues (1967) define satisfaction with security as satisfaction with "the way [the] job provides for steady employment" (p. 2). Research on job insecurity has shown that employees' perception of their job insecurity is influenced by how integral they view themselves to be to their organization (Sverke et al., 2006). For example, Sverke and colleagues (2002) showed that permanent workers have lower perceptions of job insecurity than contingent workers because they view themselves as more essential to their organization by virtue of their occupational status. When sources are sought for feedback, they should perceive themselves as integral to their organization since others are relying on them for advice to fulfill their job duties and responsibilities. In support of this, research on task interdependence has shown that when others are dependent on a person to accomplish tasks, that person perceives his or her own efforts as more important and himself or herself as more indispensable (Wittchen et al., 2007). Based on the above, being sought for feedback should facilitate opportunities for sources to experience security in their job. Accordingly, the more sources are sought for feedback, the more satisfied they should be with this facet of their job. Based on the above, the following hypothesis is put forth:

Hypothesis 2: There is a positive relationship between frequency of being sought for feedback and satisfaction with security.

Weiss and colleagues (1967) define satisfaction with creativity as satisfaction with "the chance to try [one'] own methods of doing the job" (p. 1). When sources are sought for feedback, they are provided with an opportunity to share with seekers their own ideas regarding how seekers should proceed with their work. For example, sources may suggest unique features that seekers' work should contain or unique approaches that sources should take in carrying out their work (Earley et al., 1990). In this manner, being sought for feedback should facilitate opportunities for sources to experience creativity in their job. Accordingly, the more sources are sought for feedback, the more satisfied they should be with this facet of their job. In support of the above, Sacchetti and Tortia (2013) showed that sharing knowledge and expertise (via teamwork) and expressing one's ideas freely (via involvement) are positively related to satisfaction with creativity. Both these sets of activities are related to the actions sources take when they respond to feedback-seeking requests. Based on the above, the following hypothesis is put forth:

Hypothesis 3: There is a positive relationship between frequency of being sought for feedback and satisfaction with creativity.

Journal of Organizational Psychology Vol. 19(2) 2019105 
Weiss and colleagues (1967) define satisfaction with variety as satisfaction with "the chance to do different things from time to time" (p. 2). When sources are sought for feedback, they are provided with an opportunity to engage in a different activity. Instead of focusing on getting their own work done, they divert their attention to evaluating and commenting on another employee's work. In addition to the activity itself being different, being sought for feedback may bring with it other types of variety. For example, the seeker may be someone the source does not normally interact with. In addition, the topic or subject matter of the feedback-seeking request may be different from what the source normally encounters. For example, a manager may be asked by a vice-president for feedback on a strategic issue that normally falls within the vice-president's job scope. Finally, the skills required to respond to the feedback-seeking request may be different from what the source normally uses. For example, a window washer normally works alone and applies physical skills. Responding to feedback-seeking requests, however, requires one to apply cognitive skills (to evaluate the work) and interpersonal skills (to convey the feedback response). Based on the above, being sought for feedback should facilitate opportunities for sources to experience variety in their job. Accordingly, the more sources are sought for feedback, they more satisfied they should be with this facet of their job. In support of the above, research on skill variety and job rotation has shown that utilizing different skills and performance different tasks increases job satisfaction (Griffin et al., 2001; Hackman \& Oldham, 1975). Based on the above, the following hypothesis is put forth:

Hypothesis 4: There is a positive relationship between frequency of being sought for feedback and satisfaction with variety.

\section{METHODOLOGY}

\section{Respondents}

A survey was administered in Canada to a sample of full-time working supervisors. A total of 190 surveys were distributed and 124 useable surveys were returned, yielding a response rate of $65 \%$. The sample was $51 \%$ male and $48 \%$ female. The average age was 42 years. Each of the 19 industries in the North American Industry Classification System were represented in the sample. The three largest industries were manufacturing (11\%), finance and insurance (12\%), and health care and social assistance $(13 \%)$. The average organizational tenure of respondents was 11 years and the average job tenure was six years. On average, respondents worked 44 hours per week.

\section{Measures}

Frequency of being sought for feedback. Frequency of being sought for feedback was measured with Krasman's (2018) three-item scale. The scale asks respondents to report how frequently they are sought for feedback by their subordinates (item 1), coworkers (item 2), and supervisors (item 3). The answers to these three items are then summed to arrive at a total number of times sources are sought for feedback. Respondents can answer in number of times per day or in number of times per week or in number of times per month. All answers are converted to number of times per day. A sample item is, "In total, how many times do all your subordinates ask you for feedback about their work? Please give an exact number not a range."

Job satisfaction. The facets of job satisfaction were measured with Weiss and colleagues' (1967) scales. Each scale has five items and was rated from 1 (= strongly disagree) to 5 (= strongly agree). Satisfaction with authority. A sample item is, "On my present job, this is how I feel about the chance to have other workers look to me for direction" $(\alpha=.66)$. Satisfaction with security. A sample item is, "On my present job, this is how I feel about the way my job provides for a secure future" $(\alpha=.88)$. Satisfaction with creativity. A sample item is, "On my present job, this is how I feel about the chance to try out some of my own ideas" $(\alpha=.84)$. Satisfaction with variety. A sample item is, "The chance to do many different things on the job" $(\alpha=.82)$. 
Control variables. Prior research has shown that gender can influence job satisfaction, hence it was controlled for (Okpara et al., 2005).

\section{RESULTS}

Table 1 shows the descriptive statistics, reliabilities, and intercorrelations for the variables. Each of the hypotheses was tested with hierarchical linear regression. These results are shown in Table 2.

Hypothesis 1 predicted a positive relationship between frequency of being sought for feedback and satisfaction with authority. This hypothesis was supported $(\beta=.217, \mathrm{p}<.05)$. Frequency of being sought for feedback explained $5.2 \%$ of the variance in satisfaction with authority.

Hypothesis 2 predicted a positive relationship between frequency of being sought for feedback and satisfaction with security. This hypothesis was also supported $(\beta=.216, p<.05)$. Frequency of being sought for feedback explained $9.1 \%$ of the variance in satisfaction with security.

Hypothesis 3 predicted a positive relationship between frequency of being sought for feedback and satisfaction with creativity. This hypothesis was supported as well $(\beta=.237, p<.01)$. Frequency of being sought for feedback explained $7.6 \%$ of the variance in satisfaction with creativity.

Hypothesis 4 predicted a positive relationship between frequency of being sought for feedback and satisfaction with variety. This hypothesis was not supported $(\beta=.164, p=n s)$.

TABLE 1

DESCRIPTIVE STATISTICS, INTERCORRELATIONS, AND RELIABILITIES

\begin{tabular}{|c|c|c|c|c|c|c|c|c|}
\hline Variable & $\mathrm{M}$ & SD & 1 & 2 & 3 & 4 & 5 & 6 \\
\hline 1. Gender & 1.49 & .50 & - & & & & & \\
\hline $\begin{array}{|cc|}2 . \quad \text { Frequency of being } \\
\text { sought for feedback }\end{array}$ & 2.40 & 2.59 & $.114^{-}$ & - & & & & \\
\hline $\begin{array}{|ccc|}3 . & \text { Satisfaction } \quad \text { with } \\
\text { authority } & & \\
\end{array}$ & 4.04 & .46 & $.073^{-}$ & $\begin{array}{ll}.223 \\
* \\
\end{array}$ & $(.66)$ & & & \\
\hline 4. Satisfaction with security & 3.81 & .85 & $212^{-}$ & $\begin{array}{l}.242 \\
* * \\
\end{array}$ & $\begin{array}{c}.356 \\
* * * \\
\end{array}$ & $(.88)$ & & \\
\hline $\begin{array}{|ccc|}\begin{array}{c}5 . \\
\text { creativity }\end{array} & \text { Satisfaction } \quad \text { with } \\
\end{array}$ & 3.99 & .72 & $.142^{-}$ & $\begin{array}{l}.255 \\
* \\
\end{array}$ & $\begin{array}{c}.530 \\
* * * \\
\end{array}$ & $\begin{array}{c}.446 \\
* * * \\
\end{array}$ & $(.84)$ & \\
\hline 6. Satisfaction with variety & 3.96 & .70 & $.157^{-}$ & .185 & $* * .524$ & $* * .512$ & *** .623 & $(.82)$ \\
\hline
\end{tabular}

Cronbach's alpha reliabilities appear along the diagonal.

$*=\mathrm{p}<.05 . * *=\mathrm{p}<.01 . * * * \mathrm{p}<.001$.

Gender was dummy-coded $1=$ male, $2=$ female. 
TABLE 2

HIERARCHICAL REGRESSION RESULTS

\begin{tabular}{|c|c|c|c|c|}
\hline & $\begin{array}{c}\text { Satisfaction } \\
\text { with authority }\end{array}$ & $\begin{array}{c}\text { Satisfaction } \\
\text { with security }\end{array}$ & $\begin{array}{c}\text { Satisfaction } \\
\text { with creativity }\end{array}$ & $\begin{array}{c}\text { Satisfaction } \\
\text { with } \\
\text { variety }\end{array}$ \\
\hline Step 1: & $\beta=-.073$ & $\beta=-.212^{*}$ & $\beta=-.142$ & $\beta=-.157$ \\
\hline Gender & $\beta=.217^{*}$ & $\beta=.216^{*}$ & $\beta=.237^{* *}$ & $\beta=.164$ \\
\hline Step 2: & & & & \\
\hline $\begin{array}{c}\text { Frequency } \\
\text { of being sought } \\
\text { for feedback }\end{array}$ & $5.2 \%$ & $9.1 \%$ & $7.6 \%$ & $5.1 \%$ \\
\hline \multicolumn{2}{|c|}{ R-squared } & & & \\
\hline
\end{tabular}

$*=\mathrm{p}<.05 . * *=\mathrm{p}<.01$.

Gender was dummy-coded $1=$ male, 2 = female.

\section{DISCUSSION}

Feedback-seeking occurs when a seeker attempts to solicit feedback from a source. While research has shown that feedback-seeking can benefit the seeker and the organization, little is known about its impact on the source. The purpose of this study was to increase our knowledge in this area by examining the impact of feedback-seeking on sources' job satisfaction. A survey was conducted of full-time working supervisors from various industries in Canada. Results showed that frequency of being sought for feedback was positively related to supervisors' satisfaction with authority, satisfaction with security, and satisfaction with creativity. Frequency of being sought for feedback explained $5.2 \%, 9.1 \%$, and $7.6 \%$ (respectively) of the variance in these facets of job satisfaction. Frequency of being sought for feedback was also hypothesized to be positively related to supervisors' satisfaction with variety, however, no relationship was found. It could be that feedback-seeking has become more common in workplaces, especially as organizations move away from annual performance reviews (Cappelli \& Tavis, 2016). As such, being sought for feedback may not bring with it as much uniqueness as originally hypothesized.

Despite its findings, this study has some limitations. First, because the data were cross-sectional, causality between frequency of being sought for feedback and sources' job satisfaction is not conclusive (Cook et al., 2002). Second, because the data were self-reported, respondents' answers could have been biased. To counteract this, two of Podsakoff and colleagues' (2003) recommendations were followed. First, the survey was anonymous. Second, respondents were instructed that there are no right or wrong answers. A third limitation is that common method bias may have affected the data. To counteract this, Podsakoff and colleagues' (2003) recommendation to measure the variables in reverse causal order was followed. Thus, in the survey, the items for job satisfaction appeared before the items for frequency of being sought for feedback. A final limitation is that although a wide variety of industries was represented in the sample, the findings of the study may not be fully generalizable to all employees in all organizations.

Several directions for future research are recommended. First, researchers should identify other effects that being sought for feedback may have on sources. As noted, research in this area is new, hence there is much room for further exploration. In carrying out this work, researchers should consider positive effects as well as negative effects. In addition, researchers should consider using qualitative methods such as interviewing sources about their experiences being sought for feedback. Researchers should also look more closely at the relationships uncovered in this study. Specifically, researchers should identify moderating variables that may strengthen or weaken these relationships. Researchers should consider moderators that are related to the source. For example, the positive relationship between frequency of being sought for feedback and satisfaction with security may be stronger for sources who have a greater fear of job loss (Keim et al., 2014). Researchers should also consider moderators that are related to the 
situation. For example, the positive relationship between frequency of being sought for feedback and satisfaction with creativity may be weaker in mechanistic organizational structures where there is less opportunity to carry out work in an unconventional way (Burns \& Stalker, 1961).

In terms of practical implications, this study provides further evidence that sources may be affected by feedback-seeking and, thus, that organizations should consider the impact of feedback-seeking on the source in making decisions about facilitating feedback-seeking in the workplace. With respect to such decisions, this study suggests that organizations should feel encouraged about facilitating feedbackseeking in the workplace since it may contribute to sources' job satisfaction particularly in the areas of satisfaction with authority, satisfaction with security, and satisfaction with creativity. Organizations interested in facilitating feedback-seeking in the workplace, should consider communicating to sources that feedback-seeking may enhance their job satisfaction. Consistent with social exchange theory, if sources perceive that they may gain from feedback-seeking, they may be more motivated to respond to feedback-seeking requests and to encourage others to seek feedback from them (Emerson, 1976). Organizations should also consider communicating to seekers that feedback-seeking may enhance sources' job satisfaction. Consistent with task significance theory (Hackman \& Oldham, 1976), if seekers perceive that seeking feedback may positively impact sources, they may be more motivated to seek feedback.

\section{REFERENCES}

Anseel, F., Beatty, A. S., Shen, W., Lievens, F., \& Sackett, P. R. (2015). How are we doing after 30 years? A meta-analytic review of the antecedents and outcomes of feedback-seeking behavior. Journal of Management, 41(1), 318-348.

Ashford, S. J. (1986). Feedback-seeking in individual adaptation: A resource perspective. Academy of Management Journal, 29(3), 465-487.

Ashford, S. J. (1993). The feedback environment: An exploratory study of cue use. Journal of Organizational Behavior, 14(3), 201-224.

Ashford, S. J., \& Cummings, L. L. (1983). Feedback as an individual resource: Personal strategies of creating information. Organizational Behavior and Human Performance, 32(3), 370-398.

Ashford, S. J., Blatt, R., \& Walle, D. V. (2003). Reflections on the looking glass: A review of research on feedback-seeking behavior in organizations. Journal of Management, 29(6), 773-799.

Ashford, S. J., De Stobbeleir, K., \& Nujella, M. (2016). To seek or not to seek: Is that the only question? Recent developments in feedback-seeking literature. Annual Review of Organizational Psychology and Organizational Behavior, 3, 213-239.

Ashford, S. J., Wellman, N., Sully de Luque, M., De Stobbeleir, K. E., \& Wollan, M. (2018). Two roads to effectiveness: CEO feedback seeking, vision articulation, and firm performance. Journal of Organizational Behavior, 39(1), 82-95.

Burns, T., \& Stalker, G. M. (1961). The Management of Innovation. London. Tavistock.

Cappelli, P., \& Tavis, A. (2016). The performance management revolution. Harvard Business Review, 94(10), 58-67.

Cook, T. D., Campbell, D. T., \& Shadish, W. (2002). Experimental and Quasi-Experimental Designs for Generalized Causal Inference. Boston: Houghton Mifflin.

Earley, P. C., Northcraft, G. B., Lee, C., \& Lituchy, T. R. (1990). Impact of process and outcome feedback on the relation of goal setting to task performance. Academy of Management Journal, 33(1), 87-105.

Emerson, R. M. (1976). Social exchange theory. Annual Review of Sociology, 2(1), 335-362.

Griffin, M. A., Patterson, M. G., \& West, M. A. (2001). Job satisfaction and teamwork: The role of supervisor support. Journal of Organizational Behavior: The International Journal of Industrial, Occupational and Organizational Psychology and Behavior, 22(5), 537-550.

Hackman, J. R., \& Oldham, G. R. (1975). Development of the job diagnostic survey. Journal of Applied Psychology, 60(2), 159. 
Hackman, J. R., \& Oldham, G. R. (1976). Motivation through the design of work: Test of a theory. Organizational Behavior and Human Performance, 16(2), 250-279.

Hall, J. L., Leiaecker, J. K., \& DiMarco, C. (1996). What we know about upward appraisals of management: Facilitating the future use of UPAs. Human Resource Development Quarterly, 7(3), 209-226.

Ilgen, D. R., Fisher, C. D., \& Taylor, M. S. (1979). Consequences of individual feedback on behavior in organizations. Journal of Applied Psychology, 64(4), 349.

Keim, A. C., Landis, R. S., Pierce, C. A., \& Earnest, D. R. (2014). Why do employees worry about their jobs? A meta-analytic review of predictors of job insecurity. Journal of Occupational Health Psychology, 19(3), 269.

Krasman, J. (2018). Getting to the "Source" of Feedback-Seeking: Impact of Feedback-Seeking on Supervisor Stress. International Journal of Human Resource Studies, 8(3), 103-117.

Locke, E. A. (1976). The nature and causes of job satisfaction. In M. D. Dunnette (Ed.), Handbook of Industrial and Organizational Psychology (pp. 1297 - 1349). Chicago: Rand McNally

Madzar, S. (1995). Feedback seeking behavior: A review of the literature and implications for HRD practitioners. Human Resource Development Quarterly, 6(4), 337-349.

Miller, V. D., \& Jablin, F. M. (1991). Information seeking during organizational entry: Influences, tactics, and a model of the process. Academy of Management Review, 16(1), 92-120.

Morrison, E. W. (1993). Newcomer information seeking: Exploring types, modes, sources, and outcomes. Academy of Management Journal, 36(3), 557-589.

Okpara, J. O., Squillace, M., \& Erondu, E. A. (2005). Gender differences and job satisfaction: a study of university teachers in the United States. Women in Management Review, 20(3), 177-190.

Podsakoff, P. M., MacKenzie, S. B., Lee, J. Y., \& Podsakoff, N. P. (2003). Common method biases in behavioral research: A critical review of the literature and recommended remedies. Journal of Applied Psychology, 88(5), 879.

Saari, L. M., \& Judge, T. A. (2004). Employee attitudes and job satisfaction. Human Resource Management: Published in Cooperation with the School of Business Administration, The University of Michigan and in alliance with the Society of Human Resources Management, 43(4), 395-407.

Sacchetti, S., \& Tortia, E. C. (2013). Satisfaction with creativity: A study of organizational characteristics and individual motivation. Journal of Happiness Studies, 14(6), 1789-1811.

Smith, P. C., Kendall, L. M., \& Hulin, C. L. (1969). The Measurement of Satisfaction in Work and Retirement: A Strategy for the Study of Attitudes. Oxford, England: Rand Mcnally.

Spector, P. E. (1985). Measurement of human service staff satisfaction: Development of the Job Satisfaction Survey. American Journal of Community Psychology, 13(6), 693-713.

Spector, P. E. (1997). Job satisfaction: Application, Assessment, Causes, and Consequences (Vol. 3). Sage publications.

Sverke, M., Gallagher, D. G., \& Hellgren, J. (2002). Alternative work arrangements. In Health Effects of the New Labour Market (pp. 145-167). Springer, Boston, MA.

Sverke, M., Hellgren, J., \& Näswall, K. (2006). Job insecurity: A literature review. Arbetslivsinstitutet.

Weiss, D. J., Dawis, R. V., \& England, G. W. (1967). Manual for the Minnesota Satisfaction Questionnaire. Minnesota Studies in Vocational Rehabilitation, 22, 120.

Wittchen, M., Schlereth, D., \& Hertel, G. (2007). Social indispensability in spite of temporal and spatial separation: Motivation gains in a sequential task during anonymous cooperation on the internet. International Journal of Internet Science, 2(1), 12-27. 